\begin{tabular}{|c|c|}
\hline \multicolumn{2}{|c|}{ Publisherl nfo } \\
\hline PublisherName & : BioMed Central \\
\hline PublisherLocation & : London \\
\hline Publisherl mprintName & : BioMed Central \\
\hline
\end{tabular}

\title{
Abnormal right atrial performance in surgically repaired Tetralogy of Fallot: the German Competence Network for Congenital Heart Defects investigators
}

\section{Articlel nfo}

$\begin{array}{lll}\text { ArticlelD } & : 4788 \\ \text { ArticleDOI } & : 10.1186 / 1532-429 X-17-S 1-Q 84 \\ \text { ArticleCitationID } & : \text { Q84 } \\ \text { ArticleSequenceNumber } & : 708 \\ \text { ArticleCategory } & : \text { Walking poster presentation } \\ \text { ArticleFirstPage } & : 1 \\ \text { ArticleLastPage } & : 1 \\ \text { ArticleHistory } & : \text { RegistrationDate } & : \text { 2015-2-3 } \\ & & \text { OnlineDate }\end{array}$

ArticleCopyright $\quad$ : Kutty et al; licensee BioMed Central Ltd.2015

This article is published under license to BioMed Central Ltd. This is an Open Access article distributed under the terms of the Creative Commons Attribution License (http://creativecommons.org/licenses/by/4.0), which permits unrestricted use, distribution, and reproduction in any medium, provided the original work is properly cited. The Creative Commons Public Domain Dedication waiver (http://creativecommons.org/publicdomain/zero/1.0/) applies to the data made available in this article, unless otherwise stated.

ArticleGrants

ArticleContext

: 129681717S1S1 
Shelby Kutty, Aff1

Corresponding Affiliation: Aff1

Quanliang Shang, Aff1

David Danford, Aff1

Michael Steinmetz, ${ }^{\text {Aff2 }}$

Andreas Schuster, Aff2

Titus Kuehne, ${ }^{\text {Aff3 }}$

Philipp B Beerbaum, Aff4

Samir Sarikouch, ${ }^{\text {Aff4 }}$

Aff1 University of Nebraska Medical Center, Chiildren's Hospital and Medical

Center, Omaha, NE, USA

Aff2 University Medical Center, Göttingen, Germany

Aff3 German Heart Institute, Berlin, Berlin, Germany

Aff4 Hanover Medical University, Hannover, Hannover, Germany

\section{Background}

The purpose of the study was to test the hypothesis that right atrial (RA) performance is abnormal in surgically repaired tetralogy of Fallot (TOF).

\section{Methods}

TOF patients were prospectively enrolled for same day cardiovascular magnetic resonance (CMR), echocardiography and exercise stress test following a standardized protocol in 14 participating centers of the German Competence Network for Congenital Heart Defects. Peak longitudinal RA strain (RAS), peak longitudinal right ventricular strain (RVS), RA and RV enddiastolic volumes (EDV, indexed to body surface area) and ejection fraction (EF) were measured. RAS and RVS were obtained from fourchamber cine (6segment model) using CMRfeature tracking (FT, CPAMR, Tomtec).

\section{Results}

The cohort consisted of 196 subjects: 171 patients with repaired TOF (94 male, mean age 18 \pm 8 yrs) and 25 normal controls (13 male, 35 \pm 14 years). Fiftyfour TOF patients had follow up studies at 1 year, yielding 225 TOF examinations. All subjects were in sinus rhythm. RA EDV, RAS, RVS, RA EF, and RV EF in TOF were $60 \pm 19 \mathrm{ml} / \mathrm{m2}, 14 \pm 6 \%, 13 \pm 4 \%, 33 \pm 10 \%$ and $51 \pm 8 \%$; and differed significantly from the respective indices in controls: $34 \pm 9 \mathrm{ml} / \mathrm{m} 2,30 \pm 10 \%, 21 \pm 4 \%, 51 \pm 9 \%$ and $64 \pm 9 \%$ (all $p<0.001$ ). RA EDV and RAS correlated directly with RVS (both $p<0.001$ ). RA EDV was higher in older TOF patients, while RAS did not increase with age. RA EDV, but not RAS, correlated positively with echoderived RV systolic pressure. Neither RA EDV nor RAS was associated with tricuspid regurgitation grade or VO2 max. Positive correlation was observed for RV EDV with RA EDV ( $p=0.035)$, and a trend toward negative correlation with RAS $(p=0.09)$. 


\section{Conclusions}

RAS, RA EDV and RA EF are all generally abnormal in TOF. Because they correlate with other functional $\mathrm{RV}$ indices, these abnormalities may represent RA diastolic burden from chronic RV dysfunction in TOF. The young age of the study cohort might explain the absence of RAS correlation to tricuspid regurgitation and $\mathrm{VO}_{2}$ max.

\section{Funding}

German Competence Network for Congenital Heart Defects. 